\title{
FORMAÇÃO DE MUDAS DE ALFACE EM DIFERENTES BANDEJAS E SUBSTRATOS
}

\author{
Abraão Cícero da SILVA \\ Vinicius Santos Gomes da SILVA ${ }^{1}$ \\ Bruno Campos MANTOVANELLI ${ }^{2}$ \\ Gilmara Mabel SANTOS ${ }^{3}$
}

\begin{abstract}
${ }^{1}$ Engenheiro Agrônomo, doutorando pelo Programa de Pós-Graduação em Ciência do Solo da Universidade Federal Rural de Pernambuco - UFRPE - Recife, e-mail: abraaocicero@yahoo.com.br; vinicius.agro2008.1@gmail.com ${ }^{2}$ Engenheiro Agrônomo, Doutorando pelo Programa de Pós-Graduação em Ciência do Solo da Universidade Federal de Santa Maria - UFSM- Santa Maria - e-mail: brunomantovanelli21@ gmail.com.

3Engenheira Agrônoma, Professora da Universidade Federal rural de Pernambuco - UFRPE - Unidade Acadêmica de Garanhuns.
\end{abstract}

Recebido em: 01/06/2016 - Aprovado em: 21/04/2017 - Disponibilizado em: 01/07/2017

\section{RESUMO:}

Objetivou-se com este trabalho avaliar o melhor tipo de bandeja e substrato a ser utilizado no processo de produção de mudas de alface. $\mathrm{O}$ experimento foi conduzido em casa de vegetação da UFRPE. O delineamento experimental foi em blocos casualizados em arranjo fatorial de 2 x 5 com 4 repetições. Os tratamentos consistiram de dois tipos de bandejas (polietileno e poliestireno), cinco tipos de substratos (comercial Baseplant 100\%; Húmus 50\% + Areia 50\%; substrato comercial Baseplant 33\% + Húmus 33\% + Areia 33\%; substrato comercial Baseplant 50\% + Húmus 50\% e substrato comercial Baseplant 50\% + Areia 50\%). O número de folhas foi influenciado pelo tipo de substrato, com destaque para os substratos húmus 50\% + areia 50\% e comercial Baseplant 50\% + areia 50\%, quanto a bandeja, a do tipo poliestireno proporcionou os melhores resultados para as variáveis estudadas com exceção do comprimento da parte aérea.

Palavras chave: Lactuca sativa $L$, produção, plântulas.

\section{FORMATION OF LETTUCE SEEDLINGS IN DIFFERENT TRAYS AND SUBSTRATES}

\begin{abstract}
:
The objective of this study was to evaluate the best type of tray and substrate to be used in lettuce seedlings production process. The experiment was conducted in the UFRPE greenhouse. The experimental design was a randomized block in factorial arrangement of $2 \times 5$ with 4 repetitions. The treatments consisted of two types of trays (polyethylene and polystyrene), five types of substrates (trade Baseplant 100\%, humus 50\% + sand 50\%; commercial substrate Baseplant $33 \%+$ Humus $33 \%+$ sand 33\%; commercial substrate Baseplant $50 \%$ humus $+50 \%$ and commercial substrate Baseplant $+50 \%$ Sand $50 \%$ ). The number of leaves was influenced by the type of substrate, especially the $50 \%$ humus + sand 50\% and commercial Baseplant 50\% + sand 50\%, as the tray, the polystyrene type provided the best results for the variables with except for the shoot length.
\end{abstract}

Keywords Lactuca sativa L; production; seedlings.

\section{Introdução}

A alface (Lactuca sativa L.) constitui uma das hortaliças mais cultivadas no Brasil, isso por ser uma das mais consumidas pelos brasileiros e apresentar características de boa adaptação, além de, requerer pequenas áreas para produção. É uma cultura de grande 
importância sócio - econômica, onde contribui na geração, de emprego, rendas e divisas para o país, exercendo assim um ótimo papel social, devido ao fato de contribuir para fixar o homem no campo.

A produção nacional é de aproximadamente 525 mil toneladas, sendo a região nordeste responsável por cerca de $11 \%$ do que é produzido (IBGE, 2006). Em Pernambuco, a olerícola é cultivada em sua maioria, por pequenos agricultores familiares; estes com recursos muito limitados e sem acesso à informação, não fazem os investimentos necessários na obtenção de mudas de qualidade, preparo de solo, adubações, irrigação, entre outros tratos culturais, resultando e em baixa produtividade e retorno econômico. Desse modo, alternativas que possibilitem o aumento da produção com baixo dispêndio de recursos fazem-se necessárias.

A obtenção de mudas de qualidade é indispensável para que o percentual de sobrevivência no campo e a produtividade possam ser os maiores possíveis no local de implantação da cultura (CAMARGO et al., 2011). Com isso, a produção de mudas é uma das etapas de maior importância no sistema produtivo, influenciando inteiramente no desempenho final das plantas cultivadas, tendo em vista que mudas com pouco desenvolvimento, condicionam geralmente, a obtenção de plantas com baixa qualidade, maior ciclo e aumento o custo de produção, reduzindo o lucro dos agricultores (ECHER et al., 2007).

Dentre os fatores com maior importância na formação de mudas, está a produção de alface em bandejas com posterior transplantio, segundo JAIME et al. (2001), a produção de mudas em bandejas é considerada um dos métodos mais eficientes, porque confere maior uniformidade da muda, evitando a competição entre plantas e diminuindo o estresse das raízes durante o processo de transplantio. Atualmente há no mercado bandejas de polietileno e poliestireno, apresentando variações de uso entre os produtores. Outro fator de grande importância é o substrato em que a muda será formada, pois o mesmo é quem proporcionará as condições adequadas de germinação das sementes e desenvolvimentos inicial das mudas. Portanto, torna-se um grande desafio para os produtores de alface e viveristas, encontrarem o melhor tipo de bandeja e de substrato, que irá proporcionar uma formação de mudas de melhor qualidade em menor tempo.

Diante do exposto, o objetivo desse trabalho foi avaliar o melhor tipo de bandeja e substrato a ser utilizado no processo de produção de mudas de alface Crespa.

\section{Materiais e Métodos}

O estudo foi conduzido na casa de vegetação da Unidade Acadêmica de Garanhuns, Universidade Federal Rural de 
Pernambuco (UAG/ UFRPE), no município de Garanhuns, agreste de Pernambuco (Latitude $08^{\circ} 53^{\prime} 25^{\prime \prime}$ S e Longitude $36^{\circ} 29^{\prime} 34^{\prime \prime} \mathrm{W}$ ).

$\mathrm{O}$ delineamento experimental foi $\mathrm{em}$ blocos casualizados (DBC), no esquema fatorial de 2 x 5 com 4 blocos, sendo a unidade experimental constituída de cinco plantas. Os tratamentos consistiram de dois tipos de bandejas de 200 células (polietileno e poliestireno), cinco tipos de substratos (1) comercial Baseplant 100\%, 2) húmus 50\% + areia 50\%, 3) substrato comercial Baseplant $33 \%$ + húmus $33 \%$ + areia $33 \%$, 4) substrato comercial Baseplant 50\% + húmus 50\%) substrato comercial Baseplant 50\% + areia $50 \%$.

A semeadura foi realizada utilizando a alface crespa cultivar Lechuga Simpson, semeando quatro sementes por célula, dez dias após a emergência, realizou-se o desbaste deixando apenas uma muda por célula. A irrigação foi realizada duas vezes ao dia, mantendo a umidade adequada para o desenvolvimento das mudas. Trinta dias após a germinação realizou-se a determinação da altura das plantas com régua graduada medindo da base até a última folha desenvolvida, número de folhas por meio de contagem direita, posteriormente realizou-se a colheita das plantas separando a parte aérea do sistema radicular, medindo-se o sistema radicular e a parte aérea com trena graduada. A biomassa fresca da parte aérea e das raízes foram pesadas em balança de precisão, em seguida foram levados para estufa de ventilação forçada a $60^{\circ} \mathrm{C}$ durante 72 horas, após secar foi determinado em balança de precisão a fitomassa seca da parte aérea e do sistema radicular.

Os resultados do número de folhas, altura de plantas, comprimento do sistema radicular, comprimento da parte aérea, massa fresca e seca da parte aérea e do sistema radicular foram submetidos à análise de variância, ANOVA e as médias comparadas pelo teste de Tukey, ao nível de 5\% de probabilidade usando o software SISVAR (FERREIRA, 2008).

\section{Resultados e Discussão}

Os resultados do número de folhas de alface crespa submetida a diferentes substratos em bandejas de polietileno e poliestireno são apresentados na (Tabela 1). Não houve interação significativa entre os substratos e as bandejas avaliadas.

Verificou-se para o substrato 3 (Comercial Baseplant + Areia+ Húmus) diferença significativa ao nível de $5 \%$ pelo teste Tukey entre as bandejas avaliadas, apresentado os melhores resultados quando utilizado a bandeja de poliestireno (Tabela 1). Entretanto, os melhores resultados ocorreram quando foram utilizados os substratos 1 e 2, não diferindo entre si, em bandeja de polietileno para variável avaliada, obtendo aproximadamente 5 folhas por muda. O número de folhas verificado, atendem aos 
critérios de produção de mudas, de alface que segundo FILGUEIRA (2000), em sistema de cultivo convencional a muda de alface está apta a ser transplantada quando atinge número de quatro a seis folhas definitivas, não sendo diferente no sistema de cultivo orgânico (SOUZA e REZENDE, 2006). Os resultados diferem dos obtidos por SILVA e QUEIROZ (2014), os quais estudando a formação de mudas de alface em bandejas preenchidas com diferentes substratos não encontram diferença significativa para a mistura dos diversos substratos nas bandejas com alface.

Tabela 1. Número de folhas (NF) de plântulas de alface para as bandejas de isopor e polietileno e diferentes substratos alternativos.

Bandejas

Substratos

2

3

4

5

CV
Polietileno

$4,25 \mathrm{a}^{1} \mathrm{~A}^{2}$

$4,25 \mathrm{aA}$

$4,32 \mathrm{aA}$

$4,52 \mathrm{aA}$

$4,54 \mathrm{aA}$
4,3

10,5

Poliestireno

$4,75 \mathrm{aA}$

$4,77 \mathrm{aA}$

$3,72 \mathrm{bA}$

$4,1 \mathrm{abA}$

$4,11 \mathrm{abA}$

10,5

Média Geral
4,3

${ }^{1}$ As médias seguidas pela mesma letra, na linha e coluna, não diferem estatisticamente entre si pelo Teste de Tukey ao nível a $5 \%$ de probabilidade.

No que se refere ao comprimento da parte aérea das mudas de alface não houve diferença significativas tanto para os substratos como paras os tipos de bandejas. Enquanto que, para, comprimento do sistema radicular houve diferença significativa para as bandejas, (Figura 1). A bandeja de poliestireno proporcionou desenvolvimento do sistema radicular superior à de polietileno. Esse resultado pode ser atribuído as melhores condições de umidade e temperatura proporcionada pela bandeja de poliestireno por ser um bom isolante térmico proporcionando menor oscilação de temperatura e menor perda de água por evaporação. Evitar variações de umidade do substrato é uma pratica de grande importância principalmente para culturas sensíveis como alface, pois segundo DUARTE (2012) a umidade é o principal fator limitante ao crescimento e a produção de matéria seca das plantas. 


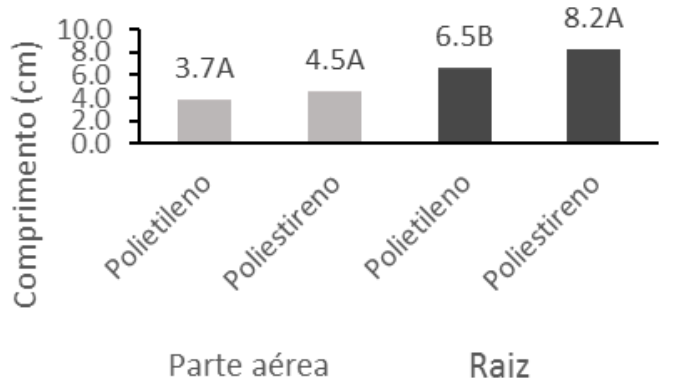

Figura 1. Comprimento da parte aérea e do sistema radicular de plântulas de alface germinadas em diferentes bandejas, polietileno e poliestireno, submetidas a análise de variância pelo teste Tukey ao nível de $5 \%$ de probabilidade.

Para as variáveis, massa fresca da raiz (MFR) e massa fresca da parte aérea (MFPA) ocorreram significância ao nível de $5 \%$ de probabilidade para as diferentes bandejas utilizadas (Figura 2). Para os diferentes substratos não houve diferença estatística para estas variáveis. Este resultado pode ser atribuído a importância da reserva de nutriente presente nas sementes, as quais são fonte de nutrientes para as plântulas na fase inicial de desenvolvimento, exercendo o substrato maior influência nas propriedades físicas. Segundo CARVALHO e NAKAGAWA (1998) uma semente em boas condições de reserva de nutriente é capaz de originar uma plântula vigorosa mesmo em condições deficientes do substrato.

Verifica-se que para as variáveis MFR e MFPA, as bandejas de poliestireno apresentaram resultados superior $0,37 \mathrm{~g}$ e $0,63 \mathrm{~g}$ quando comparadas com as bandejas de polietileno 0,2g e 0,49g (Figura 2). Esses resultados diferem dos obtidos por SPELLING et al. (2004), quando avaliaram a qualidade de mudas de alface produzidas em bandejas de polietileno e poliestireno com diferentes números de células, os autores verificaram que não houve diferença significativa para as variáveis. altura das mudas e o peso da biomassa da parte aérea.

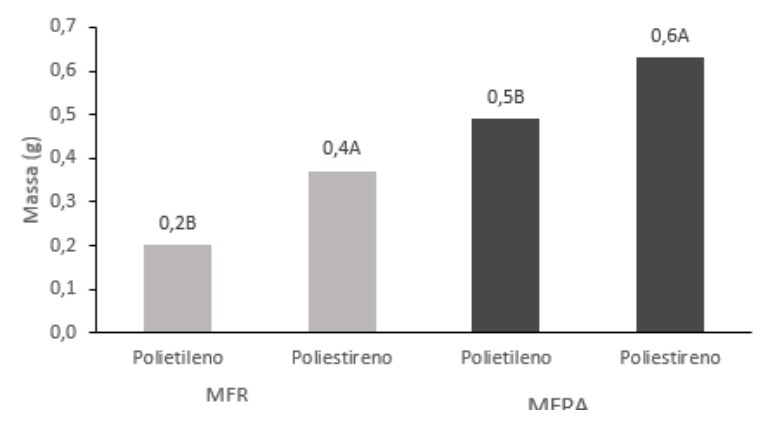

Figura 2. Massa fresca da raiz (MFR), Massa fresca da parte aérea (MFPA) de plântulas de alface germinadas em diferentes bandejas, polietileno e poliestireno, submetidas a análise de variância pelo teste de Tukey ao nível de $5 \%$ de probabilidade.

As variáveis, massa seca das raízes (MSR) e da parte aérea (MSPA), também apresentaram diferença estatística ao nível de 5 $\%$ de probabilidade para os diferentes tipos de bandejas (Figura 3). A massa seca do sistema radicular e da parte aérea das plantas foram superior para as bandejas de poliestireno quando comparado com as bandejas de polietileno. Esse resultado podem ser atribuído as altas temperatura que ocorrem na região Nordeste do Brasil e como bandeja de poliestireno (isopor) possui um sistema isolante térmico mais eficientes conforme relatos TESSARIOLI NETO (1994), possibilitou melhor desenvolvimento das 
mudas por manter melhores condições de umidade e temperatura no substrato.

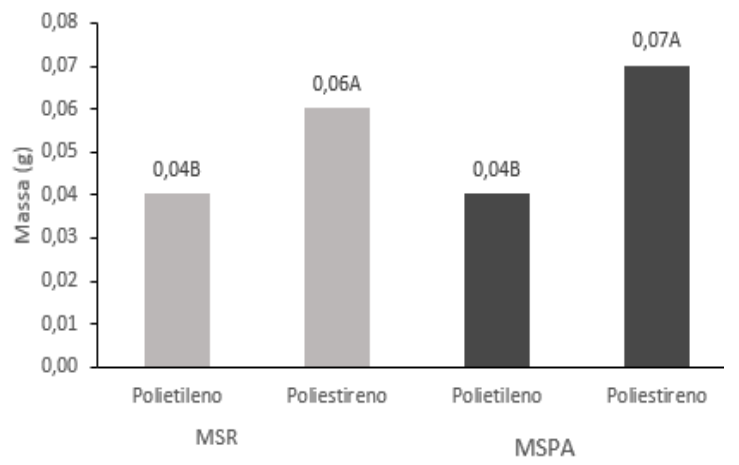

Figura 3. Massa seca da raiz (MSR), Massa Seca da parte aérea (MSPA) de plântulas de alface germinadas em diferentes bandejas, polietileno e poliestireno, submetidas a análise de variância pelo teste Tukey ao nível de $5 \%$ de probabilidade.

Para os substratos não ocorreu diferença estatística, isso possivelmente de deve ao fato de que as combinações de materiais feitas, originaram substratos semelhantes, os quais podem ter proporcionado condições físicas semelhantes para o desenvolvimento das plântulas. Resultados esses que diferem dos encontrados por Smiderle et al. (2001), cujo melhor resultado foi encontrado com o substrato Plantmax ${ }^{\circledR}$ enxerto para altura da planta.

\section{Conclusão}

Os substratos húmus $50 \%$ + areia $50 \%$ e comercial Baseplant 50\% + areia 50\% são uma alternativa para a produção de mudas de alface de boa qualidade, apresentando baixo custo, pois a areia que faz parte da mistura dos mesmo pode ser adquirida em área próximo ao viveiro a preços bem acessíveis.
A bandeja de poliestireno é a mais indicada para a produção de mudas de alfaces de maior qualidade.

\section{Referências}

CAMARGO, R.; PIRES, S. C.; MALDONADO, A. C.; CARVALHO, H. P.; COSTA, T. R. Avaliação de substratos para a produção de mudas de pinhão-manso em sacolas plásticas. Revista Trópica - Ciências Agrárias e Biológicas, v. 5, N. 1, p. 32, 2011.

ECHER, M. M.; GUIMARÃES, V.F; ARANDA, A.N; BORTOLAZZO, E.D, BRAGA, J.S. Avaliação de mudas de beterraba em função do substrato e do tipo de bandeja. Semina Ciências Agrárias, Londrina, v. 28, n. 1, p. 45-50, 2007.

FERREIRA, D.F. SISVAR: um programa para análises e ensino de estatística. Revista Symposium, Lavras, v. 6, p. 36-41, 2008.

FILGUEIRA, F. A. R. Novo manual de olericultura. Viçosa: UFV. 2000. 402p.

IBGE. Censo Agropecuário 2006. Brasil, Grandes Regiões e Unidades da Federação. Instituto Brasileiro de Geografia e Estatística, $2^{a}$ apuração, 2006.

JAIME, M.; ROBERTS, L.; Mc DONALD, M. R. Growing onion transplants in plug trays. [S.1.]: Ministry of Agriculture and Food, 2001. Disponível em <http:// www.gov.on.ca/OMAF/english/crops/facts/01019.htm>. Acessado em 7 de março de 2016.

SILVA, E. C.; QUEIROZ, R. L. Formação de mudas de alface em bandejas preenchidas com diferentes substratos. Biosci. J., Uberlândia, v. 30, n. 3, 2014.

Smiderle, O. J., Salibe, A. B., Hayashi, A. H., \& Minami, K Produção de mudas de alface, pepino e pimentão em substratos combinando areia, solo e plantmax. Horticultura

Brasileira, Brasília, v. 19, n.2, p. 386-390, 2001. 
SOUZA, J. L.; RESENDE, P. Manual de Horticultura Orgânica. Viçosa: Ed. Aprenda Fácil. 2006. 842p.

SPELLING, A. C; ARAÚJO, J. A. C;

SANCHES, C. E. J; JUNIOR, L. V .E;

HAROLDO, X .L. VOLPE, H. X. L;

Avaliação da qualidade de mudas de alface produzidas em bandejas de poliestireno e de polietileno com diferentes números de células.

Horticultura Brasileira, v. 22, n 4, 2004.

TESSARIOLI NETO, J. Mudas olerícolas de alta qualidades. In: MINANI, K.;

TESSARIOLI NETO, J.; PENTEADO, S. R.; SCARPARI, F. J. A produção de mudas hortícolas de alta qualidade. Piracicaba: Gráfica universitária de Piracicaba, 1994. P 10-15. 